\title{
DESEMPENHO ECONÔMICO-FINANCEIRO DA PETROBRAS DE 2000 A 2014
}

\author{
ECONOMIC AND FINANCIAL PERFORMANCE OF THE
}

PETROBRAS 20002014

\section{Bruno Cesar Linhares da Costa Silva}

Universidade Federal do Rio Grande do Norte - UFRN. Petrobras. Profissional nivel técnico - Administração e controle.

E-mail: brunolinhares.pj@gmail.com

\section{Fernanda Cristina Barbosa Pereira Queiroz}

Universidade Federal do Rio Grande do Norte - UFRN. Professora no Departamento de Engenharia de Produção.

E-mail: fernandacbpereira@gmail.com

\section{Jamerson Viegas Queiroz}

Universidade Federal do Rio Grande do Norte - UFRN. Professor no Departamento de Engenharia de Produção. E-mail: viegasqueiroz@gmail.com

\section{Nilton Cesar Lima}

Universidade Federal de Uberlândia - UFU. Professor na Faculdade de Ciências Contábeis. E-mail: cesarlim@yahoo.com

\section{João Agra Neto}

Universidade Federal do Rio Grande do Norte - UFRN. Professor no Departamento de

Engenharia de Produção. E-mail: joaoagra_@hotmail.com 


\section{Gestãoe \\ Desenvolvimento}

\section{RESUMO}

Este artigo tem como propósito compreender a trajetória de desempenho econômico-financeiro da Petrobras no período de 2000 a 2014. Como base metodológica adotou-se uma abordagem qualitativa e quantitativa, onde as junções dos principais indicadores e de um modelo complementaram a análise econômico-financeira da Petrobras, possibilitando uma classificação de pesquisa do tipo descritiva. Constatou-se que seu portfólio de ativos atribuiu baixa rentabilidade por conta do alto endividamento, sobretudo após o Pré-Sal. Concluiu-se que a Petrobras não representa, no atual momento, uma performance segura a um perfil conservador de investimentos de longo prazo diante de opções na aquisição de ações, cabendo um estudo futuro sobre como caracterizam-se os perfis atuais dos agentes acionistas da Petrobras.

Palavras-chave: Petrobras. Análise das Demonstrações. Desempenho econômico-financeiro.

\section{ABSTRACT}

This paper aims to understand the trajectory of economic and financial performance of Petrobras from 2000 to 2014. As methodological basis was adopted a qualitative and quantitative approach, where the joints of the main indicators and a model complemented the economic and financial analysis of Petrobras, allowing a search ranking of the descriptive type. It was found that its portfolio of assets assigned low profitability due to high debt, especially after the Pré-Sal. It's concluded that Petrobras is not at present a safe performance to a conservative profile of long-term investments on options management buyout. Fitting, in turn, a future study on how to characterize the current profile of the shareholders of Petrobras agents.

Keywords: Petrobras. Analysis of Financial Statements. Economic and financial performance. 


\section{INTRODUÇÃo}

O tema da avaliação de desempenho nas atividades organizacionais é de importância bastante consolidada, sobre a qual não se tergiversa, pois está relacionado à sobrevivência das empresas no ambiente atual de globalização e concorrência. Assim, concebe-se preliminarmente que a base para a avaliação econômico-financeiro de uma organização transita pela análise dos indicadores de desempenho, sob os quais relacionam informações com fins de transmitir fenômenos complexos de maneira simples, sobretudo dados internos da organização (VAN BELLE, 2005). Por outro lado, Cardoso e Guimarães (2014) atestam que não são eficazes as análises pontuais de indicadores econômico-financeiro passados como fonte única para melhorias econômico-financeiras futuras. Portanto, fazem-se adequadas as análises de séries históricas, de trajetórias futuras planejadas, bem como de relacionamento e integração entre outros indicadores internos e externos à organização para decisões e melhorias de performance organizacional. Porém, um dos vários campos de atuação em premissa preliminar na avaliação de desempenho organizacional é o econômico-financeiro. Para isso são utilizadas as demonstrações contábeis desenvolvidas pela organização de onde são extraídos indicadores de comportamentos passados, ou seja, de decisões passadas. Esses indicadores permitem avaliar comparativamente tanto a evolução histórica dos resultados econômico-financeiros como também a projeção de alguns resultados futuros (CATAPAN, COLAUTO, 2014). Tal fato remete-se ao entendimento de que uma análise de desempenho baseada em eventos passados permite obter algumas expectativas para o futuro e caracterizar a situação econômicofinanceira atual de uma empresa (SILVA, 2014).

Como as demonstrações contábeis são um reflexo numérico das decisõestomadas operacionalmente, os índices extraídos delas possibilitam atribuir uma avaliação a essas decisões quanto aos impactos nos parâmetros econômico-financeiros de liquidez, endividamento e rentabilidade de uma organização. Ademais, permite avaliar se as decisões operacionais estão relacionadas às decisões estratégicas (GARTNER, 2010).

Nesse contexto, a Petróleo Brasileiro S/A (PETROBRAS) é uma empresa de capital aberto, caracterizada como sociedade mista, portanto, seus acionistas se dividem entre o Estado Brasileiro acionista majoritário - e demais acionistas que atuam na bolsa (PETROBRAS, 2015). As características desses dois conjuntos de acionistas direcionam para objetivos distintos: enquanto o Estado tem uma função social, os outros acionistas objetivam geração de valor e lucro. Quanto às percepções dos acionistas que objetivam resultados (valor e lucro), estes vêm se surpreendendo nos últimos anos ao deparar-se com quanto a Petrobras tem sido criticada por deterioração de seus resultados financeiros, o que tem refletido no valor de suas ações na bolsa e, portanto, em seu valor de mercado, haja vista que o "valor da 
Petrobras caiu 50\% desde 2010" (FRIEDLANDER, LANDIM, 2014). No mês de fevereiro de 2015, a agência classificadora de risco Moody's avaliou negativamente a nota de crédito da empresa, perdendo o grau de investimento (MOODY'S, 2015).

Após a descoberta de uma grande reserva de petróleo em águas profundas da costa brasileira, a Petrobras tem aumentado seu nível de endividamento e fez um processo de capitalização em bolsa a fim de prosseguir com investimentos de exploração dessa descoberta. Entretanto, a empresa tem alcançado níveis de liquidez cada vez mais limitados. "[...] a Petrobras continuará com fluxo de caixa negativo nos próximos anos, à medida que conduz um ambicioso programa de investimentos, o que pode piorar a sua saúde financeira." (TEMÓTEO; MARTINS, 2013). O fato é que, mesmo diante de perspectivas de longo prazo de rentabilidade provenientes das novas descobertas de reservas de petróleo, a empresa não encontra respaldo nas agências de classificação de risco e no mercado que precifica suas ações. Partindo desse fato e do pressuposto de que o passado explica o presente, este trabalho de pesquisa procura responder "se os resultados econômicos passados contribuíram com a atual situação econômico-financeira da Petrobras".

Diante de uma abordagem contextual que delimita a observância do desempenho econômicofinanceiro, adotou-se como objetivo geral: compreender a trajetória de desempenho econômico-financeira da Petrobras em uma abordagem histórica e baseada em dados de avaliação de indicadores econômicofinanceiros de resultados alcançados entre 2000 e 2014.

Desta forma, o estudo encontra-se estruturado em cinco seções: após a introdução, a seção subsequente buscou abordar a avaliação do desempenho econômico-financeiro, seguidos com ênfase os indicadores: liquidez, endividamento, rentabilidade e, inclusive, com uma nova abordagem de avaliação da liquidez através do modelo de Flueriet; já na seção três, tem-se o delineamento metodológico adotado na pesquisa sobre como os dados foram analisados; na seção quatro são apresentados os resultados da análise dos balanços patrimoniais e demonstrativos de resultados com enfoque nos indicadores propostos; e, na sequência, a seção cinco apresenta a discussão desses resultados, finalizando com as considerações acerca dos indicadores e possíveis reflexos contributivos à trajetória econômico-financeira da empresa.

\section{Avaliação de Desempenho Econômico-Financeiro}

A avaliação econômico-financeira das empresas éconcebida a partir das relações entre contas egrupo de contas das demonstrações contábeis divulgadas pelas empresas de onde são formulados indicadores e comparados com padrões de forma a auxiliar com informações o fornecimento de diagnósticos presentes 
ou futuros que contribuam para o processo decisório das empresas, ou seja, são relatórios utilizados como meio de tomada de decisão para todas as partes interessadas no negócio (gestores, acionistas, credores e investidores) (CARVALHO, BIALOSKORSKI NETO, 2008; NASCIMENTO et al., 2012; FERREIRA, 2012; SILVA et al., 2013). Sendo assim, os indicadores são provenientes das demonstrações contábeis, refletem os resultados de decisões operacionais no empreendimento e apresentam sua situação patrimonial. Apesar de as demonstrações por si só já trazerem informações importantes, somente por meio de sua análise e interpretação de indicadores é possivvel obter informações mais eficientes e melhores, ou seja, útil às partes interessadas (NASCIMENTO et al., 2012; SILVA et al., 2013).

Já o processo de análise financeira consiste em transformar minunciosamente dados apresentados nas demonstrações contábeis em informações que geram capacidade de decisão (NASCIMENTO et al., 2012; FERREIRA, 2012; SILVA et al., 2013). Por outro lado, mensurar os resultados de ações adotadas em um período determinado e focar recursos complementados por um planejamento desenvolvido a partir da percepção da eficácia da gestão representa elemento fundamentalista para uma avaliação econômica da organização (NASCIMENTO et al., 2012). Verificando as definições das diferentes denominações de categorias de indicadores de análise econômico-financeiras apresentadas por Lima Neto (2011), Nascimento et al. (2012), Silva et al. (2013), Plais (2010) e Khatchatourian e Treter, (2010), apreende-se que tais índices podem ser aglutinados da seguinte forma:

a) Estrutura de Capital (Endividamento): representando a relação entre capitais próprios, advindos dos sócios e acionistas, e de terceiros, provenientes de absorção de dívidas. O monitoramento da estrutura de capital está diretamente relacionado em como se encontram os níveis de endividamento, imobilização e alavancagem, contribuindo com as decisões de obtenção e aplicação de recursos.

b)Liquidez (ou Capacidade de Pagamento): revela a capacidade de pagamento de compromissos constantes nos passivos circulantes e não-circulantes, ou seja, no curto e no longo prazo.

c) Rentabilidade (ou Eficiência de Ativos, ou Lucratividade): configura-se numa métrica de avaliação do retorno econômico das operações da companhia, ou seja, quão exitosos são os resultados econômicos, fornecendo significado de atratividade no âmbito financeiro.

Assim, conhecer a situação econômico-financeira de uma organização por meio da avaliação de suas demonstrações contábeis fundamenta-se em metodologias que buscam abordar três aspectos que a definem economicamente: liquidez, rentabilidade e endividamento (MARION, 2010). Nesse aspecto, há um conjunto de indicadores que permitem descrever de forma básica o desempenho econômico empresarial, Tabela 1. 


\begin{tabular}{l|l}
\multicolumn{2}{l}{ Tabela 1 - Indicadores de nível introdutório e nível intermediário } \\
\hline $\begin{array}{l}\text { Nivel Introdutório } \\
\text { Liquidez: Corrente, Seca e Geral }\end{array}$ & Nivel Intermediário \\
$\begin{array}{l}\text { Rentabilidade: da empresa e do } \\
\text { empresário }\end{array}$ & Produtividade e outros \\
$\begin{array}{l}\text { Endividamento: quantidade e } \\
\text { qualidade }\end{array}$ & Lucratividade \\
& $\begin{array}{l}\text { Necessidade de capital de giro } \\
\text { e outros } \\
\text { Análise de Fluxo de Caixa } \\
\text { Rotatividade (Atividade) } \\
\text { Análise DoAR } \\
\text { Alavancagem Financeira } \\
\text { Outros índices de } \\
\text { endividamento }\end{array}$ \\
\hline
\end{tabular}

Fonte: Marion (2010)

Desse modo, considerando o propósito desta pesquisa respaldada na descrição da situação econômica, nos níveis de endividamento e estado de liquidez da Petrobras, baseado na Tabela 1, serão utilizados todos os indicadores de nivel introdutório - para fins de análise global - e os indicadores intermediários de Necessidade de Capital de Giro e Alavancagem Financeira - para fins complementares de análise. Há que se considerar que o princípio de investigação de relações de causa e efeito que caracteriza o Modelo de Du Pont serão transversais a todos os indicadores aplicáveis a esta presente investigação (FERNANDES, FERREIRA, RODRIGUES, 2014).

\subsection{INDICADORES DE ENDIVIDAMENTO}

Partindo da contribuição apresentada por Marion (2010), os indicadores de endividamento existem no sentido de atribuir valor para a quantidade e a qualidade da dívida de uma organização. Excesso de uso de capitais de terceiros torna a empresa sensivel a mudanças e, se esse endividamento for com recursos de curto prazo, os riscos de insolvência são ainda maiores. Similarmente, Matarazzo (2008), Marion (2010) e Assaf Neto (2015) apresentam diversos indicadores para acompanhamento do endividamento em nivel de quantidade. Um deles, chamado por Marion (2010) como indicador Grau da Dívida e por Assaf 
Neto (2015) como indicador de Endividamento, é capaz de avaliar a quantidade de capitais de terceiros mediante a razão entre Capitais de Terceiros e Patrimônio Líquido:

$$
\text { Grau da dívida }=\frac{\text { Exigivel Total }}{\text { Património Líquido }}
$$

No que se refere a avaliar a qualidade da dívida, os indicadores se voltam a verificar a composição do endividamento, ou seja, a participação de capitais de curto prazo na dívida total (MARION, 2010):

$$
\text { Composição do Endividamento }=\frac{\text { Passivo circulante }}{\text { Exigivel Total }}
$$

O indicador de Imobilização dos Capitais Permanentes apresentado por Assaf Neto (2015) mensura o quanto do ativo permanente é financiado por recursos de longo prazo, ou seja, se os recursos de longo prazo são o bastante para financiar o ativo permanente:

$$
\text { ImobilizaçãodosCapitaisPermanentes }=\frac{\text { AtivoPermanente }}{\text { PatrimônioLíquido }+ \text { ExigivelaLongoPrazo }}
$$

\subsection{INDICADORES DE LIQUIDEZ TRADICIONAL}

Os indicadores de liquidez se apresentam no intuito de permitir conhecer a situação financeira de uma organização, o que significa verificar a capacidade de honrar as obrigações financeiras no curto, médio e longo prazo (MARION, 2010; ASSAF NETO, 2015).

O indicador de Liquidez Corrente verifica essa capacidade no curto prazo pela relação entre o Ativo Circulante e o Passivo Circulante, ou seja, o quanto tem de recursos de curto prazo para cada recurso de dívida (MARION, 2010; ASSAF NETO, 2015):

$$
\text { LíquidezCorrente }(L C)=\frac{\text { Ativocirculante }}{\text { Passivocirculante }}
$$




\section{Gestãoe \\ Desenvolvimento}

e-ISSN: 2446-6875

p-ISSN: 1807-5436

A Liquidez Seca verifica essa mesma capacidade considerando recursos de mais liquidez, no caso, excluindo os estoques tendo em vista que estes sofrem de perecibilidade, de obsolescência e podem ser manipulados para melhorar indicadores (MARION, 2010; ASSAF NETO, 2015):

$$
\text { Liquidez Seca }(L S)=\frac{\text { Ativo Circulante-Estoque }}{\text { Passivo Circulante }}
$$

A mensuração da capacidade de uma organização honrar todos os compromissos de curto prazo apenas com os recursos imediatos é chamada de Liquidez Imediata. Trata-se, portanto, de indicador que relaciona disponibilidades com o passivo circulante. Geralmente, as organizações não obtêm altos índices desse indicador, pois não é interessante economicamente manter altos volumes de recursos financeiros disponíveis (MARION, 2010; ASSAF NETO, 2015):

$$
\text { LiquidezImediata }(L I)=\frac{\text { Disponivel }(\text { Caixa }+ \text { Bancos }+ \text { Aplicaçōesdecurtoprazo })}{\text { PassivoCirculante }}
$$

A Liquidez Geral é um indicador de avaliação de longo prazo da capacidade de a empresa honrar todas as suas dívidas, relacionando recursos e dívidas de curto e longo prazos (MARION, 2010; ASSAF NETO, 2015):

$$
\text { LiquidezGeral }(L G)=\frac{\text { AtivoCirculante }+ \text { RealizávelaLongoPrazo }}{\text { Passivocirculante }+ \text { ExigivelaLongoPrazo }}
$$

\subsection{MODELO DE FLUERIET}

O modelo de Fleuriet é uma nova abordagem acerca da avaliação da liquidez em contraponto ao modelo de indicadores de liquidez tradicional. Conforme Kitzberger e Padoveze (2004), aos modelos de análise de liquidez tradicional, o de análise de Flueriet é complementar. No modelo de Flueriet, parte-se do pressuposto de que há uma inadequação do modelo tradicional na definição da situação financeira 
de uma empresa devido ao fato de relacionar conjuntos de contas do circulante que possuem naturezas distintas, ou seja, que algumas das contas são construídas e desconstruídas de forma não diretamente relacionada ao ciclo operacional, o que pode caracterizar uma falsa situação de solvência (AMBROZINI; MATIAS; PIMENTA JUNIOR, 2014; KITZBERGER; PADOVEZE, 2004).

Nesse sentido, para o desenvolvimento do modelo, apresenta-se um novo modelo de balanço no qual se separam as contas do circulante em dois subgrupos relacionados com a atividade operacional (ativo e passivo operacionais) das contas cujas naturezas são financeiras (ativo e passivo financeiro). As outras contas do ativo e do passivo são agrupadas como ativo permanente e passivo permanente, respectivamente (AMBROZINI, MATIAS, PIMENTA JUNIOR, 2014; KITZBERGER, PADOVEZE, 2004). A diferença entre o valor do Ativo Operacional (AO) e o Passivo Operacional (PO) determina as necessidades de recursos para financiar o giro dos negócios às Necessidades de Capital de Giro (NCG):

$$
N C G=A O-P O
$$

A diferença entre o Passivo Permanente (PP) e o Ativo Permanente (AP) define os recursos que irão financiar o NCG, ou seja, o Capital de Giro (CDG):

$$
C D G=P P-A P
$$

E a diferença entre o Ativo Financeiro (AF) e Passivo Financeiro (PF) caracteriza a sobra ou não de recursos do CDG após este financiar o NCG, ou seja, o Saldo de Tesouraria (ST):

$$
S T=A F-P F
$$

O ST positivo ou não estabelece a situação de liquidez da organização como saudável ou não, respectivamente (AMBROZINI; MATIAS; PIMENTA JUNIOR, 2014; KITZBERGER; PADOVEZE, 2004). Um contínuo e crescente ST negativo caracteriza um fenômeno conhecido por Efeito Tesouro, quando as NCG exigem mais CDG que o disponivel, o que leva a financiar as atividades operacionais (permanentes) com 
recursos de curto prazo. Aumentos de imobilização de recursos de longo prazo (redução do CDG disponível) e/ou crescimento das atividades operacionais (aumento de NCG por overtrade) são as principais causas desse efeito (ASSAF NETO, 2015).

\subsection{INDICADORES DE RENTABILIDADE}

A análise de rentabilidade tem por objetivo atribuir valor à situação econômica da organização, ou seja, à eficiência da composição do ativo organizacional em gerar resultado, lucro e em remunerar o capital próprio. Por isso, há dois indicadores relacionados: Retorno sobre Investimento (ROI) e Retorno sobre Patrimônio Líquido (ROE). O ROI mensura a rentabilidade do negócio, das operações da organização, enquanto o ROE mensura a rentabilidade do capital próprio. Conforme apresentado por Marion (2010) e Matarazzo (2008), há diversas formulações para o cálculo do ROI em virtude da complexidade de se alcançar a exata taxa de retorno operacional, que exclui os efeitos de atividades financeiras. Portanto, essas formulações se diferenciam pelos conceitos do lucro (lucro líquido, lucro bruto, lucro operacional, etc.) e do investimento (patrimônio líquido, ativo operacional, ativo total, etc.) e, consequentemente, por resultados de taxas de retorno mais ou menos representativos. Entretanto, quanto mais representativos, mais complexo o processo de obtenção, de forma que Marion (2010) utiliza o princípio de coerência: utilizar lucro líquido se utilizar ativo total, utilizar lucro operacional se utilizar ativo operacional. Assim, o ROI, para Marion (2010), é determinado pela razão entre o Lucro Líquido e o Ativo Total, e o ROE pela razão entre o Lucro Líquido e o Patrimônio Líquido:

$$
\begin{gathered}
R O I=\frac{\text { Lucro Líquido }}{\text { Ativo Total }} \\
R O E=\frac{\text { Lucro Liquido }}{\text { Patrimônio Líquido }}
\end{gathered}
$$

Além disso, o ROI de uma companhia é alcançado mediante a composição de outros dois elementos: a margem de lucro ou lucratividade e o giro do ativo ou produtividade. 0 primeiro trata-se da quantidade de lucro gerado para cada unidade de receita de venda alcançada. E o segundo, de quantas vezes a receita representa o ativo ou, em outras palavras, quantas vezes o ativo girou gerando receitas. Portanto, avaliar 
o ROI é verificar tanto o comportamento das receitas, despesas e custos (margem de lucro) como a eficiência dos investimentos realizados (giro do ativo) (MARION, 2010; ASSAF NETO, 2015):

$$
R O I=\frac{\text { Lucro Líquido }}{\text { Receitas de Vendas }} X \frac{\text { Receitas de Vendas }}{\text { Ativo Total }}
$$

Outro indicador importante no âmbito da análise de rentabilidade é o Grau de Alavancagem Financeira que verifica o impacto dos financiamentos de terceiros na remuneração do patrimônio líquido, provocado pela diferença entre retorno e o custo da dívida. Custos da dívida menores que ROI incrementam o ROE. Custos da dívida maiores que o ROI decrescem o ROE. Sendo assim, o Grau de Alavancagem é dado pela razão entre o ROE e o ROI de forma que, quando maior que 1, significa alavancagem dos rendimentos dos proprietários (MARION, 2010; ASSAF NETO, 2015):

$$
\text { Grau de Alavancagem }=\frac{R O E}{R O I}
$$

Nesta seção, foi abordado o referencial teórico relacionado com o tema da pesquisa que, por sua vez, oferece suporte ao tópico seguinte, onde são apresentados os aspectos metodológicos.

\section{Metodologia}

A metodologia pela qual este estudo se alicerça volta-se para a análise e interpretação integrada de indicadores contábeis provenientes de Balanços Patrimoniais e Demonstrativos de Resultados da Petrobras entre os anos 2000 e 2014 a fim de se construir uma compreensão histórica e estratégica da organização em estudo. Portanto, tem-se um trabalho de características de ordem descritiva na finalidade de apresentar aspectos econômico-financeiros de um determinado cenário (ACEVEDO, 2006). Nesse sentido, este trabalho também se ampara na pesquisa quantitativa - os indicadores - para produzir parâmetros para a definição da pesquisa qualitativa, a qual busca apreender as causas e relações para o cenário que se quer entender.

Sendo assim, fez-se uso da abordagem do estudo de caso, uma vez que se trata de um "estudo profundo e exaustivo de um ou poucos objetos, de maneira que permita seu amplo e detalhado 
conhecimento" (GIL, 2009, p. 54). Para tanto, valeu-se, como etapa seguinte deste trabalho, da pesquisa bibliográfica para fundamentar os métodos de análise e a interpretação dos resultados obtidos e, em seguida, com fins de tratamento analítico, fez-se uso da pesquisa documental das Demonstrações Financeiras da companhia onde são sistematizadas e divulgadas pelo Instituto Assaf (2015). Daí o fato de a metodologia anteceder à abordagem teórica, pois a mesma foi tratada na sequência, como ordem do método a ser abordado no estudo e concepção teórica encontrada para sua fundamentação. De posse das demonstrações, formularam-se indicadores - fundamentados na pesquisa bibliográfica - mediante os enfoques tradicionais de análise nas categorias de estrutura de capital (Grau de Endividamento, Composição do Endividamento e Imobilização de Capitais Permanentes), rentabilidade (Retorno sobre Investimentos, Retorno sobre capitais próprios, Alavancagem Financeira e Análise de Margem e Giro) e liquidez (Liquidez Corrente, Liquidez Seca, Liquidez Imediata e Liquidez Geral) e, para este último, também a utilização do Modelo de Fleuriet, para cada ano do período de estudo. Com a compreensão dos resultados dos indicadores, fazem-se as conclusões acerca do desempenho da empresa em cada categoria de análise (estrutura de capital, liquidez e rentabilidade), seguido por conclusão do desempenho econômico-financeiro global mediante integração dos resultados das categorias.

Ainda, na consecução desta metodologia, a análise das demonstrações contábeis requisitou um tratamento prévio, pois, conforme apresentado por Grecco, Geron e Formigoni (2009), as Leis n 11.638/07 e n 11.941/09 alteraram práticas contábeis a partir de 2008 a fim de convergir as normas brasileiras às normas internacionais. Dito isto, considerando que o período de análise desta pesquisa inclui anos antes e após essas alterações, garantiu-se a comparabilidade das demonstrações concebendo como padrão as demonstrações contábeis a partir de 2008 e considerando que:

a) Contas e grupos de contas contábeis de mesma nomenclatura são comparáveis;

b) Contas e grupos de contas que não existem simultaneamente entre demonstrações não são comparáveis;

c) Ativo Realizável a Longo Prazo e Ativo Permanente formam o Ativo Não Circulante; e

d) Passivo Exigível a Longo Prazo forma o Passivo Não Circulante;

As contas de "Resultados de Exercícios Futuros" e "Participações de Acionistas Minoritários" são constituintes do Patrimônio Líquido.

Após destacar qual tratamento metodológico, os indicadores de análise e o alinhamento aos padrões das demonstrações contábeis, dado o período abrangido, e considerando ainda os principais conceitos referenciados, o resultado dessa análise será apresentado na seção a seguir. 


\section{Resultados encontrados}

A Petrobras foi fundada em 03/10/1953, e atua como empresa integrada de energia nos setores de exploração e produção, refino, comercialização, transporte, petroquímica, distribuição de derivados, gás natural, energia elétrica, gás-química e biocombustiveis. Trata-se de uma sociedade de economia mista cujo maior acionista é a União Federal e líder do setor petrolífero brasileiro. Durante o período de pesquisa, 2000 a 2014, a empresa passou por três diferentes governos federais: o primeiro de 2000 a 2002, o segundo de 2003 a 2010 e o terceiro de 2011 a 2014. Houve, nesse período, 5 presidentes: 0 primeiro de 2000 a 2001, o segundo de 2002 a 2003, o terceiro de 2003 a 2005, o quarto de 2005 a 2012 e o quinto de 2012 a 2014. Considerando que o principal acionista é a União Federal, tal análise preliminar é relevante para a pesquisa, uma vez que políticas públicas possam servir de elementos em comparabilidade aos resultados encontrados neste estudo. Em 2007, foi descoberta a maior jazida de petróleo do Brasil, em águas ultra profundas e em camada Pré-sal. Para fazer frente aos investimentos dessa nova fronteira petrolífera, a companhia realiza, em 2010, o maior aumento de capital do mundo no montante de $\mathrm{R} \$ 120,2$ bilhões mediante comercialização de novas ações em bolsa de valores. Apesar dessa capitalização, a divida da Petrobras atinge, em 2014, o valor total de US\$132.158,00 milhões. Em avaliação dessa dívida, as agências de risco rebaixaram as notas da companhia.

\subsection{GRAU DA DÍVIDA}

Entre 2000 e 2002, o Grau da Dívida apresenta variações acentuadas entre os maiores índices de todo o histórico (Gráfico 1). A partir de 2003 até 2007 (ano de descoberta das reservas de petróleo do Pré-Sal), mantém tendência de redução, por aumento em maiores proporções dos capitais próprios - especialmente, reservas de lucros e capital social. Entre 2007 e 2009, verificou-se o aumento na participação de capitais de terceiros, que se deve a aumentos em maiores proporções de passivos não circulantes - especificamente, empréstimo. Em 2010, aumenta a participação de capitais próprios, reduzindo a proporção de capitais de terceiros. Esse aumento de capitais próprios deve-se ao aumento de capital ocorrido em 2010 com a emissão de novas ações em bolsa como medida de financiamento para os investimentos de exploração das reservas descobertas da camada Pré-Sal. Mesmo com essa fonte de financiamento, a partir de então, o grau da dívida mantém crescimento - baseado em empréstimos no passivo não circulante - atingindo, em 2014, o mesmo grau de dívida de 2001, ou seja, para cada R\$ 1,00 real de capital próprio, a companhia tinha 1,55 de capitais de terceiros. Em outras palavras, as dividas representam, nesse ano, $155 \%$ do capital próprio. 


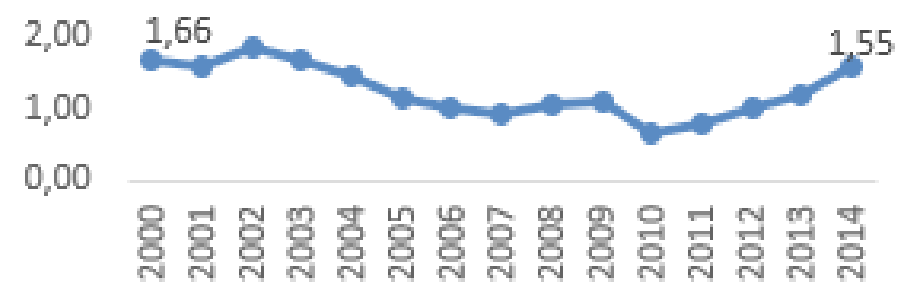

Fonte: Dos autores

\subsection{IMOBILIZAÇÃO DE CAPITAIS PERMANENTES}

O indicador de Imobilização de Capitais Permanentes busca verificar quanto dos capitais permanentes está financiando o ativo permanente. Quanto maior for, menos recursos disponiveis para financiar o ativo circulante, ou seja, menos capital de giro. Trata-se de uma forma de avaliar a qualidade de financiamento do ativo. O Gráfico 2 mostra a trajetória desse indicador. Desde 2001 até 2007, verifica-se a tendência de crescimento do uso dos recursos de longo prazo para financiamento do ativo permanente, com consequente redução da disponibilização de capital de giro. Há uma relativa estabilização desse indicador a partir de 2007, atingindo, em 2014, uma imobilização de 86\% dos recursos de longo prazo, ou seja, com disponibilização de 14\% de recursos de capital de giro. O fato é que, entre 2000 e 2014, houve um aumento de imobilização de recursos permanentes em 53,6\% ou, em outras palavras, redução do financiamento de ativo circulante em $68,18 \%$. Isso sugere que havia uma grande ociosidade de capital de giro no início do período de análise ou que, ao longo do período de análise, construiu-se uma situação financeira restrita para financiamento das necessidades de giro.

Gráfico 2 - Imobilização de capitais permanentes

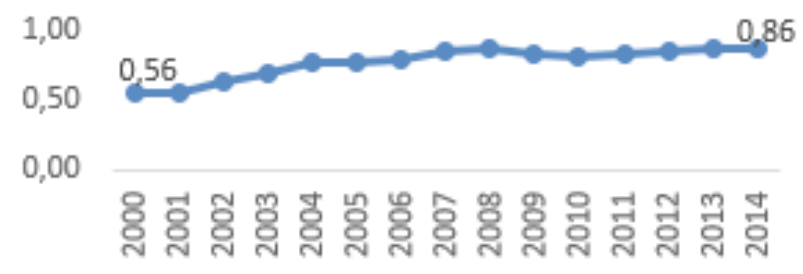

Fonte: Dos autores 


\subsection{COMPOSIÇÃO DO ENDIVIDAMENTO}

Todos os indicadores anteriores exerceram a função de avaliar a quantidade de dívida e precisam ser complementados por uma avaliação da qualidade dessa dívida, ou seja, do quanto é dívida de curto prazo e longo prazo. $O$ indicador Composição do Endividamento apresenta isso mediante a verificação de quanto do capital de terceiros é composto por passivos circulantes. O Gráfico 3 mostra a trajetória desse indicador e demonstra a tendência no longo prazo de menor participação de recursos de curto prazo na composição da dívida, representando 17\% em 2014, quando era $48 \%$ em 2000 . Isso significa que, no ano de $2014,83 \%$ da dívida era composta por recursos de longo prazo, enquanto em 2000 era $52 \%$.

\section{Gráfico 3 - Composição da dívida}

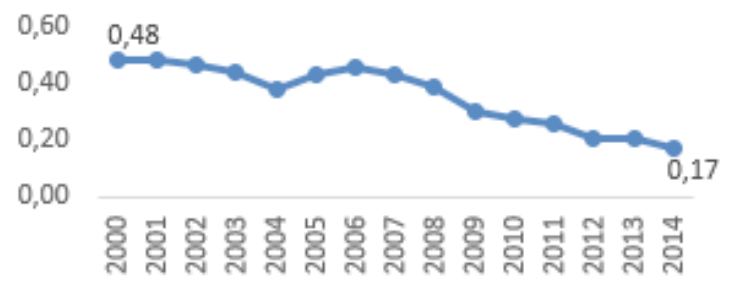

\section{Fonte: Dos autores}

Apesar da tendência geral apresentada pelo Gráfico 3 ser de redução da participação de recursos de curto prazo, verifica-se que, entre 2004 e 2006, há um aumento dessa participação, orientado pela redução dos passíveis exigíveis de longo prazo - principalmente, empréstimos - com aumento do passivo circulante nesse período.

\subsection{LIQUIDEZ CORRENTE}

A análise de liquidez corrente volta-se a avaliar globalmente a situação da disponibilidade de recursos de curto prazo capazes de honrar os compromissos também de curto prazo. O Gráfico 4 mostra o comportamento desse indicador ao longo dos anos entre 2000 e 2014. Durante esse período de análise, a companhia sempre apresentou o indicador maior que 1,00, o que significa que sempre manteve uma margem de segurança de recursos para atenuar variações de receitas ou despesas que pudessem ocorrer, prejudicando a solvência da empresa no curto prazo, ou seja, possuía capital circulante líquido positivo. Mesmo assim, esse capital circulante líquido variou bastante no decorrer dos anos deste estudo. Nos 
anos de 2007 e 2008, a companhia alcançou os menores índices de liquidez corrente do período de análise, quando praticamente igualou os montantes do ativo circulante e do passivo circulante: 1,12 e 1,06 , respectivamente. Isso corresponde a um comprometimento de $89,3 \%$ e $94,3 \%$, respectivamente, do ativo circulante com o passivo circulante. Nos 7 anos anteriores (2000-2006), esse comprometimento se manteve entre $64,5 \%$ (2001) e 82,6\% (2000), mantendo-se com pequenas variabilidades de 2003 a 2006 : entre $69,4 \%$ (2004) e 71,4\% (2006). Em 2010, ano de emissão de novas ações em bolsa, a empresa alcança 0 maior valor desse indicador $(1,89)$, ou seja, o menor nível de comprometimento do ativo circulante $(52,9 \%)$.

\section{Gráfico 4 - Liquidez Corrente}

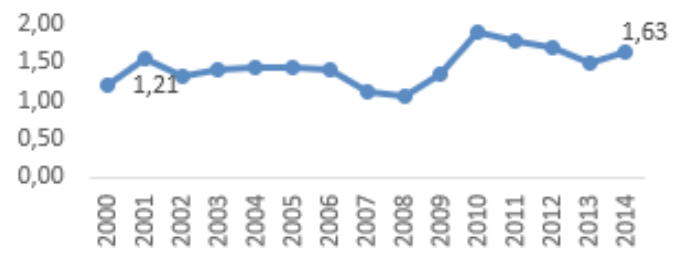

Fonte: Dos autores

\subsection{LIQUIDEZ SECA}

A liquidez seca procura mensurar a capacidade da empresa de honrar compromissos de curto prazo eliminando da análise a conta de estoque, em virtude de suas incertezas inerentes relacionadas à perecibilidade, obsolescência emanipulação no balanço, o que o torna com menor liquidez. Ocomportamento desse índice ao longo do tempo é apresentado no Gráfico 5. Pode-se perceber que é similar ao indicador anterior ao expor pontos de inflexão semelhantes, demonstrando que a conta estoque pouco impacta no perfil de liquidez da companhia. Contudo, os valores absolutos dos indicadores diminuíram, de forma que, em 15 anos de análise, 4 anos (2000, 2002, 2007 e 2008) tiveram valores menores que 1. Considerando que essa situação não é constante e que as obrigações possuem vencimentos em diversos prazos, a situação financeira da empresa, em âmbito geral, não se altera em relação ao que fora apresentado com o indicador de liquidez corrente. 


\section{Gráfico 5 - Liquidez Seca}

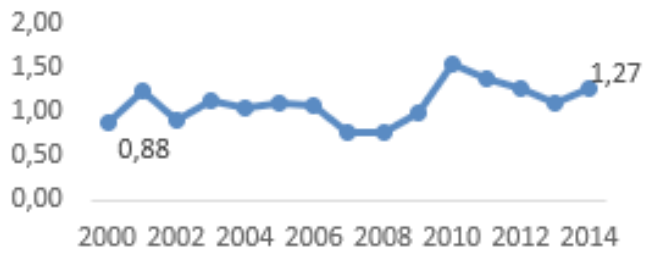

\section{Fonte: Dos autores}

\subsection{LIQUIDEZ IMEDIATA}

A liquidez imediata verifica a liquidez da empresa considerando apenas as disponibilidades imediatas em comparação ao passivo circulante. O Gráfico 6 demonstra a evolução desse indicador entre 2000 e 2014 e evidencia que sempre se apresenta menor que 1, situação comum por não ser atrativo economicamente manter recursos financeiros em caixa em grandes montantes. Além disso, o gráfico ratifica a importância das disponibilidades para a acentuada redução dos indicadores de liquidez anteriores nos anos de 2007 e 2008.

\section{Gráfico 6 - Liquidez Imediata}

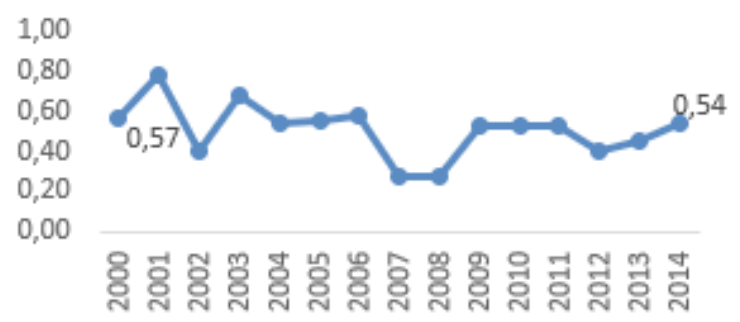

Fonte: Dos autores

\subsection{LIQUIDEZ GERAL}

O indicador Liquidez Geral avalia a capacidade da empresa de honrar seus compromissos de curto e longo prazo à medida que relaciona tudo que se transformará em dinheiro (em curto e longo prazo) com 
todas as dividas (de curto e longo prazo). O comportamento desse indicador, apresentado no Gráfico 7, mostra a tendência de decréscimo da capacidade de liquidez da empresa diante de seus compromissos totais.

Gráfico 7 - Liquidez Geral

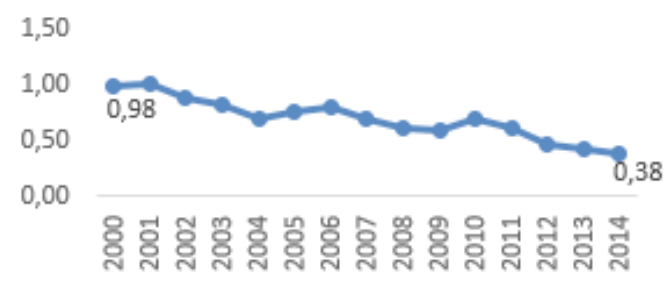

Fonte: Dos autores

Considerando que a análise de liquidez de curto prazo apresentada nos indicadores anteriores não demonstra esse comportamento de inclinação negativa, a causa para a diminuição da liquidez geral está nos ativos e passivos de longo prazo. Ainda, como o grau de endividamento cresceu no período, principalmente, em virtude de aumento de dívida de longo prazo - conforme demonstrado na análise de endividamento -, infere-se que a redução da liquidez geral se deve ao aumento do passível exigivel a longo prazo, especificamente, empréstimos e financiamentos. Nota-se, também, uma mudança na taxa de crescimento do Passivo Exigivel a Longo Prazo, a partir do ano imediatamente posterior à descoberta das reservas do Pré-sal (2008), vinculando o aumento desse item de balanço aos investimentos para prospecção dessas reservas.

\subsection{MODELO DE FLUERIET}

Para a análise de liquidez utilizando o método de Fleuriet, fez-se necessário configurar o balanço conforme as premissas do método: separando o ativo e passivo circulantes em ativos e passivos operacionais e financeiros, ou seja, nos ativos e passivos resultantes diretos das atividades operacionais e nos ativos e passivos de natureza financeira. Com isso, determina-se os indicadores de Necessidades de Capital de Giro (NCG), Capital de Giro (CDG), Saldo de Tesouraria (ST) e Índice de Liquidez (IL). O Gráfico 8 mostra a relação das NCG e do CDG no período de 2000 a 2014. O CDG mantém-se suficiente e superior às NCG entre 2000 e 2006. Nos anos de 2007 e 2008, há uma acentuada diminuição do CDG disponível a ponto de não suprir às NCG, alcançando ST negativo, corroborando com o aumento de imobilização dos 


\section{Gestãoe \\ Desenvolvimento}

e-ISSN: 2446-6875

p-ISSN: 1807-5436

capitais de longo prazo apresentado na análise de endividamento. Isso significa que nesses anos recursos não cíclicos, considerados de curto prazo, financiaram atividades cíclicas, consideradas de longo prazo, ou seja, os recursos operacionais não conseguiram financiar as atividades operacionais. Há uma melhora dessa relação em 2009, seguida por acentuado aumento de CDG em 2010, ano em que ocorre o aumento de capital da companhia. A partir de então, há sempre ST positivo, o que denota a existência de recursos para suprir necessidades de crescimento operacional.

\section{Gráfico 8 - Necessidades de Capital de Giro x Capital de Giro}

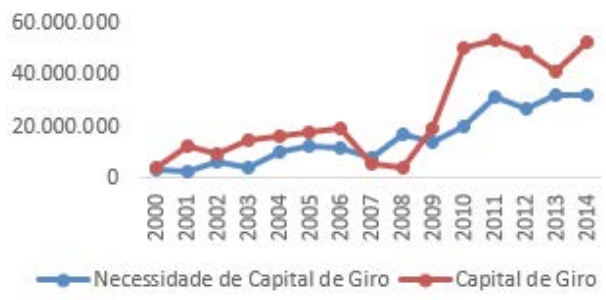

Fonte: Dos autores

Verificando o Gráfico 8, percebe-se que a redução de CDG ocorrida em 2007 e 2008 deve-se a aumento de ativo permanente, especificamente em imobilização, já que este possui maior representatividade no ativo permanente. Mais uma vez, essa informação corrobora com o aumento de imobilização de recursos de longo prazo identificado na análise de endividamento. E a correção em 2009 dessa situação ocorreu por aumento de dívida de longo prazo, seguida por aumento de capital, em 2010, e continuidade de aumento de dívida nos anos seguintes.

\subsection{RETORNO SOBRE INVESTIMENTO (ROI)}

Este indicador verifica a capacidade da organização de gerar retorno para cada valor investido, ou seja, quanto ganha de lucro por valor investido no ativo, ou, ainda, a eficiência do negócio. O Gráfico 9 mostra a trajetória desse indicador no período de análise e demonstra o seguinte:

a) Entre 2000 e 2008, o indicador varia entre 14,84\% e 8,33\%, mas não apresenta tendências de aumento ou diminuição;

b) A partir de 2009, a tendência de trajetória do indicador é negativa, apresentando valores menores a cada ano, atingindo, em 2010, o menor valor até então e, em 2014, o menor de todo o período desta análise. 


\section{Gestãoe \\ Desenvolvimento}

Com isso, apreende-se que, a despeito de variações do indicador entre 2000 e 2008, a partir de 2009 - dois anos após à descoberta das reservas de petróleo do Pré-Sal -, há uma constante deterioração da capacidade da empresa de gerar valor.

Além disso, o ROI é também influenciado por outros dois indicadores que contribuem no aprofundamento da análise: a margem de lucro líquido e o giro do ativo. O Gráfico 10 apresenta a trajetória de ambos e demonstra que:

a) a maior parte do ROI da empresa advém do giro do ativo;

b) não há grandes variações da margem de lucro da organização em análise, mas, entre 2010 e 2012, há uma leve tendência de queda, com estabilização em 2013 e acentuado decréscimo em 2014; e

c) o giro do ativo decresce acentuadamente em 2009 e 2010, seguindo controladamente outro nível de valores a partir de então.

\section{Gráfico 9 -Retorno sobre Investimentos}

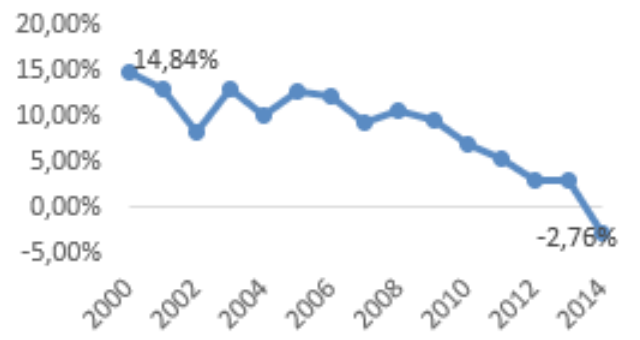

Fonte: Dos autores

Gráfico 10 - Margem de Lucro x Giro do ativo

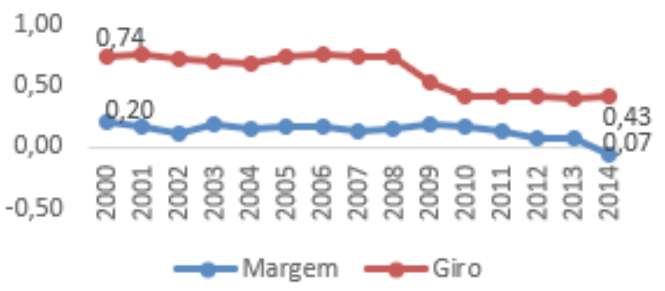

Fonte: Dos autores 
Disso se entende que a redução do ROI, a partir de 2009, se dá inicialmente da redução significativa do nível giro do ativo combinado, posteriormente, a partir de 2010 até 2012, com leves reduções da margem de lucro e que foi acentuada em 2014. Sendo o giro do ativo o componente mais representativo do ROI da empresa, reduções dele significam reduções acentuadas do ROI. O Gráfico 10 compara o crescimento percentual acumulado a partir de 2000 das variáveis que compõem o Giro do Ativo (Receita de Vendas e Ativo) e a Margem de Lucro (Lucro Líquido e Receita de Vendas). A análise desse gráfico em conjunto com as análises anteriores permite verificar que:

a) em 2009, a redução do ROI se deve à redução do Giro do Ativo em virtude de diminuição da receita de vendas combinado à aumento do ativo;

b) em 2010, a redução do ROI se deve à redução do Giro do Ativo por aumento do ativo - capitalização da empresa na bolsa;

c) em 2011 e 2012, a redução do ROI se deve à redução da Margem de Lucro por redução do lucro líquido;

d) em 2012 e 2013, o ROI mantém relativamente estável devido ao crescimento relativamente proporcional das variáveis apresentadas no Gráfico 11; e,

e) em 2014, a redução da Margem de Lucro ocorre por redução do lucro líquido.

\section{Gráfico 11 - Receita de vendas x Ativo Total x Lucro Líquido}

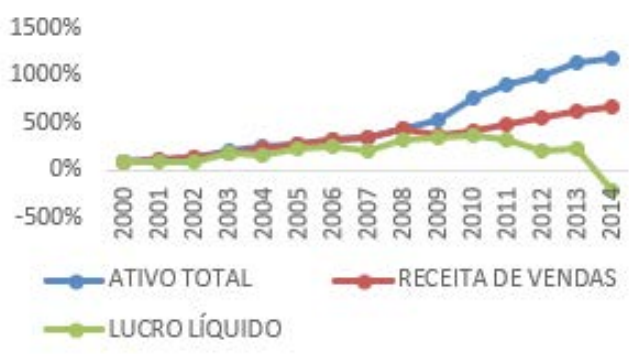

\section{Fonte: Dos autores}

A redução do lucro líquido entre 2010 e 2012 ocorreu em virtude de maiores custos dos produtos e aumento de despesas financeiras, enquanto a redução em 2014 ocorreu devido a aumento de despesas operacionais. Já a principal causa da redução do ROI da organização está na redução de nível de giro do ativo devido, predominantemente, ao aumento do ativo em proporções maiores que a receita de vendas. Esta, conforme Gráfico 11, diminuiu seu patamar a partir de 2009, contribuindo com a redução do giro. 


\subsection{RETORNO SOBRE O PATRIMÔNIO LÍQUIDO (ROE)}

O Gráfico 12 apresenta o comportamento do indicador Retorno sobre Patrimônio Líquido (ROE) no intuito de avaliar a trajetória de retornos para o capital investido pelos acionistas. É possível constatar que, no geral, a tendência do indicador foi de redução ao longo do tempo. O Gráfico 13 compara o crescimento percentual acumulado a partir do ano 2000 das variáveis que compõem o ROE (Lucro Líquido e Patrimônio Líquido) e mostra que a tendência de queda do ROE se apresenta devido a aumentos acentuados do patrimônio líquido aliado a lucros líquidos que não acompanharam proporcionalmente esse crescimento.

\section{Gráfico 12 - Retorno sobre o patrimônio líquido}

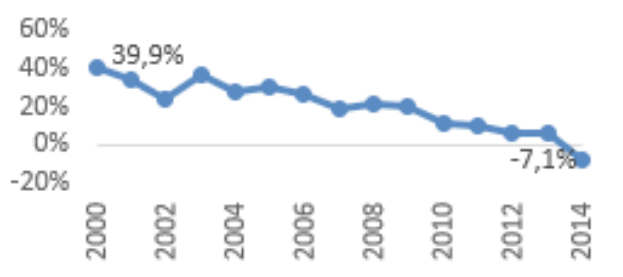

Fonte: Dos autores

\section{Gráfico 13 - Lucro líquido x Patrimônio Líquido}

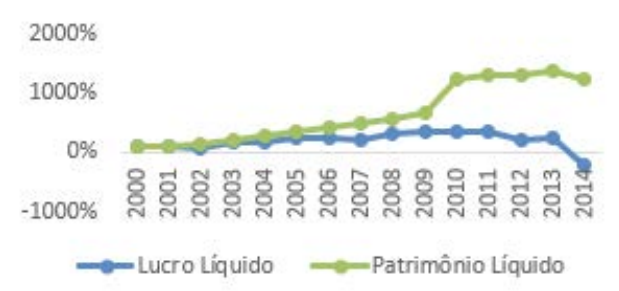

Fonte: Dos autores

\subsection{ALAVANCAGEM FINANCEIRA}

A comparação do ROE e do ROI possibilita avaliar se os capitais de terceiros estão ou não contribuindo para o aumento da remuneração dos capitais próprios. O Gráfico 14 apresenta o comportamento da alavancagem entre 2000 e 2014 e demonstra que, ao longo desse período, a alavancagem foi sempre superior a 1,00, o que significa que os capitais de terceiros sempre contribuíram para o aumento da 
remuneração do patrimônio líquido. Por consequência, pode-se afirmar que o custo dos capitais de terceiros foi sempre menor que o ROl e essa diferença - ponderada pela razão da dívida e do patrimônio líquido - remunerou os capitais próprios.

\section{Gráfico 14- Grau de Alavancagem Financeira}

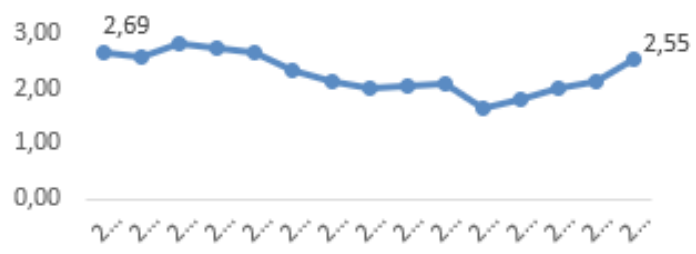

Fonte: Dos autores

A análise conjunta do Gráfico 14 e do Gráfico 15 - que compara o crescimento percentual acumulado a partir do ano 2000 das variáveis Ativo Total e Patrimônio Líquido - permite afirmar que a tendência de diminuição da alavancagem entre 2004 e 2007 é devida à diminuição do ritmo de crescimento do ativo, retomado entre 2007 e 2009, motivo da estabilidade da alavancagem. Esta, em 2010, reduz-se acentuadamente em virtude do aumento do capital ocorrido nesse ano pela emissão de novas ações. Entre 2010 e 2014, a alavancagem sobe continuamente em virtude de crescimento mais eminente do ativo.

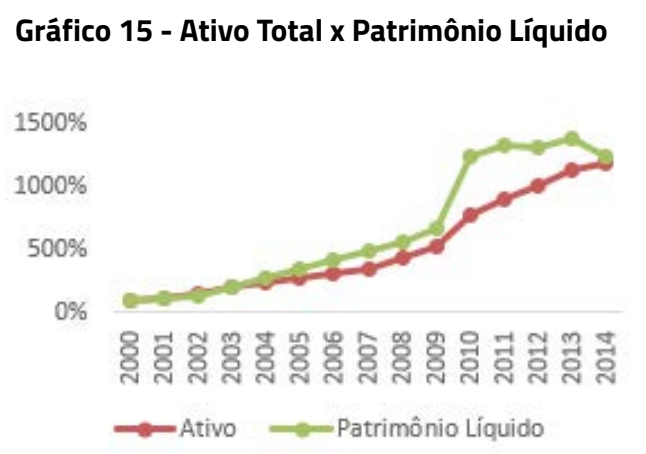

\section{Fonte: Dos autores}

Os gráficos apresentados possibilitaram o entendimento de que a empresa, em seu portfólio de ativos, atribui baixa rentabilidade por conta do alto endividamento apresentado, sobretudo após o PréSal, e tal constatação se confirmou ao analisar a margem de lucro líquido e o giro do ativo adicionalmente. A seção seguinte discute os dados encontrados frente ao referencial teórico considerado para a pesquisa. 


\section{Discussão dos resultados}

Observou-se que a trajetória do desempenho econômico financeiro da Petrobras pode ser sistematizada conforme Figura 1.

Figura 1 - Trajetória do desempenho econômico da Petrobras entre os anos 2000 e 2014

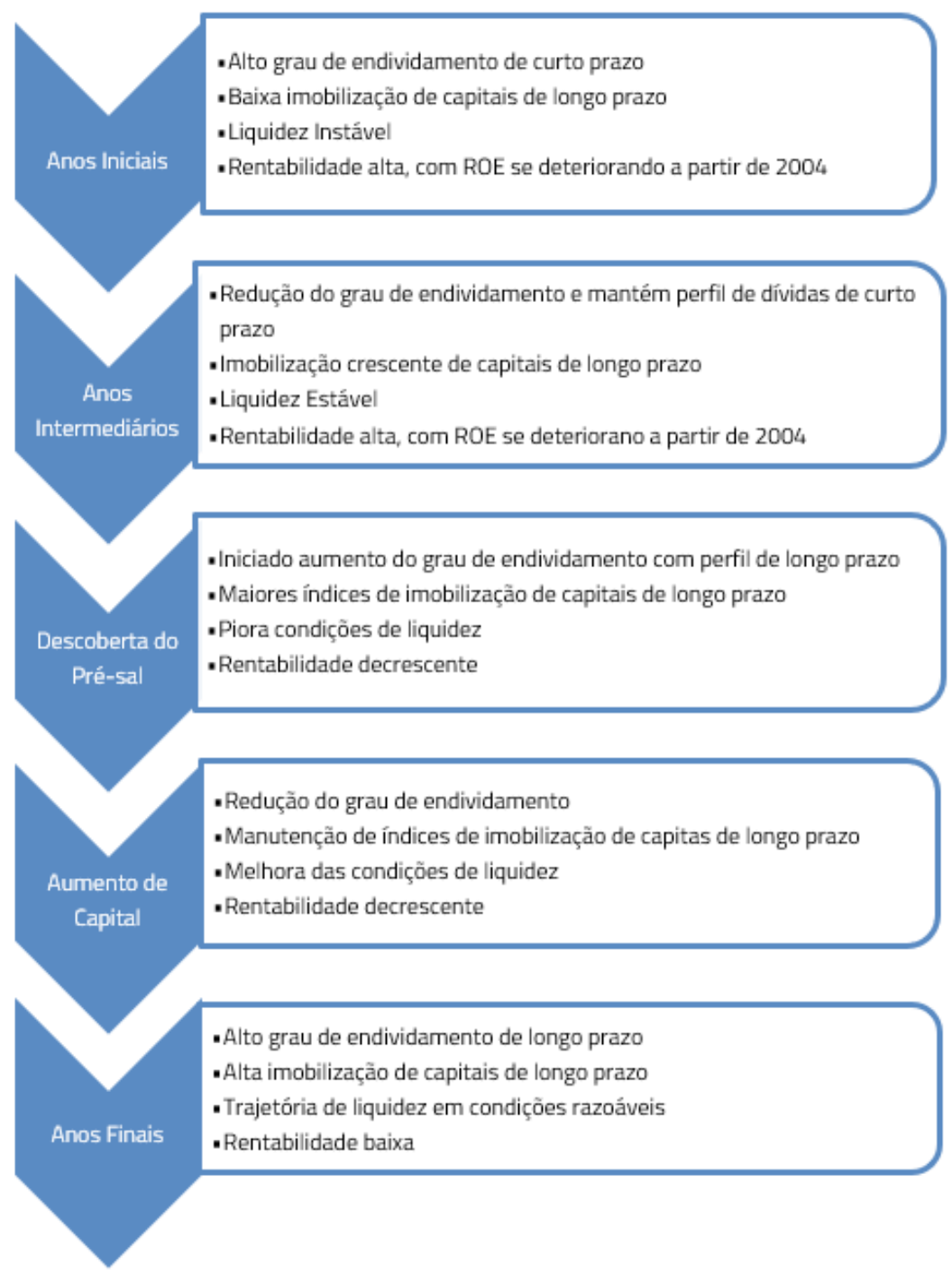

\section{Fonte: Dos autores}


Nos anos iniciais, a alta disponibilidade de capital de giro, devido à baixa imobilização de capitais de longo prazo, e o alto grau de endividamento de curto prazo são dois aspectos ligados à liquidez instável, porém, compensados por uma alta rentabilidade que contribui com lucros não distribuídos para melhorar o perfil e o grau da dívida e da liquidez. Nos anos seguintes, a situação evolui reduzindo o grau de endividamento, diminuindo a disponibilização de capital de giro, em virtude do aumento da imobilização de capitais de longo prazo, e com a liquidez estabilizada e rentabilidade garantida. Depois, quando são descobertas as reservas de petróleo do Pré-sal, inicia-se aumento do endividamento novamente, mas agora com perfil de dívida de longo prazo. Nesse período, a rentabilidade começa a decrescer e atingem-se os maiores índices de imobilização de capitais de longo prazo, ou seja, os menores índices de disponibilização de capital de giro, de forma que pioram consideravelmente as condições de liquidez. Em seguida, a companhia implementa o aumento de capital por meio de venda de ações e, como consequência, reduz o grau de endividamento e melhoram as condições de liquidez. Entretanto, mantém o nível de imobilização dos capitais permanentes e a rentabilidade continua decrescente. Nos anos finais que se seguem, o grau de endividamento continua a crescer e retoma índices dos anos iniciais, apesar de agora o perfil ser de longo prazo. As condições de liquidez são razoáveis, as imobilizações de capitais permanentes se mantêm altas e a rentabilidade continua a diminuir. O fato é que a situação atual se constitui na associação de alto grau de endividamento com baixa rentabilidade, o que não é saudável, pois retira perspectivas de redução tanto do grau quanto dos valores absolutos da própria dívida, conforme o índice de Liquidez Geral já demonstra com sua tendência negativa. Essa situação é apenas aceitável no caso do grau de endividamento se justificar por perspectivas de aumento de receitas, em proporções compativeis com posterior capacidade de pagamento das dívidas, e aumento de lucros, também em proporções compativeis com a redução do grau de endividamento e capacidade.

Por fim, diante de uma análise complementar, dada a adoção do Modelo de Flueriet, e aproximandose do entendimento de Kitzberger e Padoveze (200), Ambrozini, Matias e Pimenta Junior (2014), constatouse que a situação financeira deve ser cautelosamente analisada dada a possibilidade de inferir uma falsa situação de solvência, em virtude das contas do circulante possuírem naturezas distintas e não estarem diretamente relacionadas ao ciclo operacional.

\section{Considerações Finais}

Em uma abordagem de conhecimento do passado para entendimento do presente, este trabalho de pesquisa se pôs a conhecer a trajetória de desempenho econômico-financeiro da Petrobras entre os anos 
2000 e 2014, contribuindo com uma abordagem mais analítica da companhia. Para tanto, foi utilizada, neste estudo empírico, a compreensão de conceitos de avaliação de desempenho organizacional, em virtude de serem capazes de exercerem um importante papel de descrever cenários de resultados de uma empresa, bem como possibilitar o entendimento acerca da eficiência e competitividade das organizações. Esse papel se coadunou com os objetivos deste estudo de tal modo que a operacionalização da avaliação a que este trabalho se propôs requereu a utilização de indicadores como mecanismo de atribuição de valor aos aspectos e períodos que se definiu para análise, pois indicadores se adequam aos processos de detectar causas e analisar tendências. Sendo assim, como a avaliação de desempenho desta pesquisa se voltou ao âmbito econômico-financeiro, os indicadores descreveram os cenários de performance a partir dos dados apresentados em cada balanço patrimonial e demonstrativo de resultados da companhia dos anos 2000 a 2014. A investigação pormenorizada dos indicadores foi desenvolvida para entendimento das mudanças de cenários apresentados, de modo que inferir sobre uma trajetória à vista dos desempenhos abordados por indicadores econômico-financeiros é elemento norteador, tal como as decisões inferiram ao longo dos 15 anos na Petrobras, e que culmina numa análise mais sistêmica e fundamentada para que complexidades possam arguir a rumos contundentes de sua efetividade organizacional.

Ademais, os indicadores escolhidos abrangeram todos os aspectos definidos pela teoria como determinantes da situação econômico-financeira de uma organização (estrutura de capital, liquidez e endividamento), como também suas inter-relações. Ao mesmo tempo considerou-se o próprio contexto em que se insere a empresa no período de análise e que norteia o propósito de pesquisa: as mudanças de gestão, as mudanças de governo, a descoberta de novas reservas de petróleo em águas profundas na camada Pré-sal, a constituição do capital, o aumento de capital em bolsa, o endividamento, as avaliações das agências de risco e também o período que rege as novas normatizações contábeis.

Assim, para cada aspecto de análise da situação econômico-financeira foram aplicados os indicadores definidos, de forma que se permitiu a comparação entre eles ao longo do período determinado para diagnóstico. Logo, os períodos anteriores foram a base de comparação para a atribuição de importância relativa e, assim, obteve-se informação útil para o objetivo da pesquisa. Essa análise temporal demonstrou que a empresa tomou decisões de investimentos que hoje formam um portfólio de ativos de baixa rentabilidade. Enquanto esse portfólio não significar aumentos de receitas e lucros compativeis com os investimentos, essa situação materializa o risco do negócio que é imputado à companhia nas decisões de financiamento por endividamento quando há a possibilidade de frustação de receitas e de lucros aliados à possibilidade de não haver flexibilidade de corte de despesas proporcionais às frustações e/ou de não haver interesse pelos bancos para renovação das dívidas. Outra analítica considerada neste estudo é que tais aspectos abrangentes do resultado demonstram que o agente acionista com perfil 
investidor passa a ser caracterizado nessa nova era da companhia (Pré-sal) como especulador ou trader, agente predominante do mercado secundário, pois, a partir da análise deste estudo, busca por ações de retorno mais rápido, uma vez que os resultados econômico-financeiros não coadunam em serem muito promissores no longo prazo. Haja vista que estoque de dívida não se caracteriza problema quando há o fluxo de pagamento requerido por ele, portanto, a baixa rentabilidade aponta para fluxo de pagamentos restritos.

Essa conclusão atribui juízo de valor dos resultados em comparação referencial com períodos anteriores da própria companhia, mas não permite fazer o mesmo no que se refere à razoabilidade dos resultados dentro do mercado de atuação, o que também significa compará-los com empresas de mesmo porte e de alcance mundial. Dessa forma, sugere-se, como pesquisa complementar, a definição de padrões de indicadores do setor a fim de construir comparativos e verificar o posicionamento da companhia no contexto em que atua, bem como investigar se a companhia na era inicial do Pré-Sal atribui um capital especulativo predominante a um agente trader, e não de característica de investidor de longo prazo. Ainda, como melhoria, é recomendável que se desenvolva o indicador de rentabilidade dos ativos (ROI) da companhia com a complexidade necessária à obtenção dos resultados operacionais que excluem os efeitos das atividades financeiras. O mesmo também pode ser feito na obtenção do grau de alavancagem, mediante formulação dos indicadores de alavancagem operacional e alavancagem financeira. Em adição, pode-se desenvolver análises de fluxo de caixa a fim de inferir conclusões acerca da capacidade de pagamento pela companhia do nível de estoque de dívida atual.

\section{REFERÊNCIAS}

ACEVEDO, C. R. Monografia no curso de administração: guia completo de conteúdo e forma. 2. ed. São Paulo: Atlas, 2006.

AMBROZINI, M. A.; MATIAS, A. B.; PIMENTA JÚNIR, T. Análise dinâmica de capital de giro segundo o modelo de Flueriet: uma classificação das empresas brasileiras de capital aberto no período de 1996 a 2013. Revista Contabilidade Vista \& Revista, Belo Horizonte, v. 25, n.2, p.15-37, maio/ago., 2014.

ASSAF NETO, A. Estrutura e análise de balanços: um enfoque econômico-financeiro. 11 ed. São Paulo: Atlas, 2015.

CARDOSO, M. V.; GUIMARÃES, R. G. Modelo de avaliação de desempenho para PMEs de desenvolvimento de videojogos e animação. REUNA, Belo Horizonte, v.19, n. 5, p.137-160, 2014. 
CARVALHO, F. L. de; BIALOSKORSKI NETO, S. Indicadores de avaliação de desempenho econômico em cooperativas agropecuárias: um estudo em cooperativas paulistas. Organizações Rurais \& Agroindustriais, Lavras, v. 10, n. 3, p.420-437, 2008.

CATAPAN, A.; COLAUTO, R. D. Governança Corporativa: uma análise de sua relação com o desempenho econômico-financeiro de empresas cotadas no Brasil nos anos de 2010-2012. Contaduría y Administración, v. 59, n. 3, p.137-164, 2014.

FERNANDES, F.; FERREIRA, M. E.; RODRIGUES, E. R. Análise de rentabilidade utilizando o modelo Dupont: estudo de caso em uma operadora de planos de saúde. Revista de Gestão em Sistemas de Saúde, v. 3, n.2, p.30-44, 2014.

FERREIRA, R. do N. Governança corporativa e desempenho: uma análise em empresas brasileiras de capital aberto. Tese. 2012. (Doutorado em Administração) - Universidade Federal de Lavras, Lavras.

FRIEDLANDER, D; LANDIM, R. Valor da Petrobras caiu 50\% desde 2010. São Paulo, 23/03/2014. Folha de São Paulo. Disponível em: <http://www1.folha.uol.com.br/poder/2014/03/1429513-valor-da-petrobras-caiu-50-desde-2010.shtml>. Acesso em: 17 fev. 2016.

GARTNER, I. R. Modelagem multi atributos aplicados à avaliação do desempenho econômico-financeiro de empresas. Pesquisa Operacional, v.30, n.3, p. 619-636, 2010.

GIL, A.; C. Como elaborar projetos de pesquisa. 4. ed. São Paulo: Atlas, 2009.

GRECCO, M. C. P.; GERON, C. M. S.; FORMIGONI, H. 0 impacto das mudanças nas práticas contábeis no nivel de conservadorismo das companhias abertas brasileiras. In: Congresso Brasileiro de Custos, 16, 2009, Fortaleza. Anais... Fortaleza: Associação Brasileira de Custos, 2009. Não paginado.

INSTITUTO ASSAF NETO. Demonstrativos Contábeis da Petróleo Brasileiro S/A de 2000 a 2014. Disponivel em: <http://www.institutoassaf.com.br/2012/painel.aspx>. Acesso em: 05 nov. 2015.

KHATCHATOURIAN, O.; TRETER, J. Aplicação da lógica fuzzy para avaliação econômico-financeira de cooperativas de produção. Journal of Information Systems and Technology Management, v. 7, n. 1, p.141-162, 2010.

KITZBERGER, H.; PADOVEZE, C. L. Integração do Modelo Flueriet com a Abordagem Tradicional de Análise das Demonstrações Contábeis. Pensar Contábil, v. 6, n. 23, p. 14-20, 2004.

LIMA NETO, L. de. Análise da situação econômico-financeira de hospitais. O mundo da saúde, São Paulo, v. 35, n. 3, p.270-277, 2011 
MARION, J. C. Análise de Demonstrações Contábeis: contabilidade empresarial. 5. ed. São Paulo: Atlas, 2010

MATARAZZO, D. C. Análise financeira de balanço: abordagem básica e gerencial. 6. ed. São Paulo: Atlas, 2008.

MOODY'S.Rating Action. Moody's downgrades Petrobras ratings to Ba2: maintains review for downgrade. Nova York, 24/02/2015. MOODY'S. Disponivel em: <https://www. moodys.com/research/Moodys-downgrades-Petrobras-ratings-to-Ba2-maintains-review-for-downgrade--PR_319021?cy=bra\&lang=pt>. Acesso em: 12 fev. 2016.

NASCIMENTO, E. M.; OLIVEIRA, M. C.; MARQUES, V. A.; CUNHA, J. V. A. Ativos intangiveis: análise do impacto do grau de intangibilidade nos indicadores do desempenho empresarial. Enfoque: Reflexão Contábil, v. 31, n. 1, p.37-52, 2012.

PETROBRAS. Relacionamento com Investidores - Capital Social - Composição do capital social. Acesso em 05/11/2015. Disponivel em: <http://www.investidorpetrobras.com.br/pt/governanca-corporativa/ capital-social>. Acesso em: 10 fev. 2016.

PLAIS, P, M. Os impactos da nova metodologia de contabilização, no Brasil, dos ativos biológicos e dos derivativos (futuros) sobre os principais indicadores utilizados nas análises econômico-financeiras feitas por instituições financeiras para fins de financiamento de empresas do setor de commodities agrícolas. Revista de Finanças Aplicadas, v.1, sem paginação, 2010.

SILVA, S. S.; OLIVEIRA, M. R.; SOUZA, M. R. N.; SOUZA, W. A. R.; MENDONÇA, M. B. Avaliação do desempenho econômico-financeiro das empresas de economia mista do estado do Amazonas. CAP Accounting and Management, v. 7, n. 7, p.151-164, 2013.

SILVA, G. C. da. Análise do desempenho econômico-financeiro de empresas da região do Vale do Taquari-RS. Monografia (Graduação em Ciências Contábeis) - Centro Universitário Univates, Lajeado, 2014.

TEMÓTEO, A.; MARTINS, V. Petrobras continuará cm fluxo de caixa negativo nos próximos anos. [S.I], 04/10/2013. Disponivel em: <http://www.correiobraziliense.com.br/app/noticia/economia/2013/10/04/ internas_economia,391654/petrobras-continuara-com-fluxo-de-caixa-negativo-nos-proximos-anos. shtml>. Acesso em: 8 jan. 2016.

VAN BELL EN, H. M. Indicadores de sustentabilidade: uma análise comparativa. Rio de Janeiro: FGV, 2005. 